\title{
Analysis of the Dependence of the Apparent Sound Reduction Index on Excitation Noise Parameters
}

\author{
Ervin Lumnitzer ${ }^{1}$, Miriam Andrejiova ${ }^{2} \mathbb{D}$ and Anna Yehorova ${ }^{1, *}$ \\ 1 Department of Process and Environmental Engineering, Faculty of Mechanical Engineering, \\ Technical University of Kosice, 04022 Kosice, Slovakia; ervin.lumnitzer@tuke.sk \\ 2 Department of Applied Mathematics and Informatics, Faculty of Mechanical Engineering, \\ Technical University of Kosice, 04022 Kosice, Slovakia; miriam.andrejiova@tuke.sk \\ * Correspondence: anna.yehorova@tuke.sk
}

Received: 29 October 2020; Accepted: 27 November 2020; Published: 29 November 2020

check for updates

\begin{abstract}
In acoustic practice, established methods of measuring the acoustic properties of partition structures are used. Recommended procedures and means can be found in technical standards, but practice suggests that measurement results may also depend on measurement conditions. These procedures leave the choice of noise type, frequency interval examined, and excitation interval on the measurer. The aim of this research is to determine which parameter has a significant effect on the results, and to quantify the extent of this effect. We examined the type of noise, the frequency band of the sound passing through the partition structure and the excitation interval of the diffusion field in the rooms (hereinafter referred to as "excitation interval"). During the research, we conducted a number of repeated, statistically significant measurements, which we first evaluated by classical methods used in acoustic practice. We subjected the obtained results to a thorough mathematical analysis. Evaluation of the results shows that some measurement conditions significantly affect the resulting values, especially in the low-frequency spectrum. One of the most important elements which has an effect on the results is the type of excitation noise, which, when assessed in the source room, excites the diffuse sound field, and its transmission through the considered partition structure is measured. The significance of the investigated frequency interval was also demonstrated.
\end{abstract}

Keywords: apparent sound reduction index; frequency spectrum; white and pink noise; excitation interval; planning of experiments; regression models

\section{Introduction}

At present, the demand of the population for improving the quality of life is generally increasing. The field of acoustics is an extremely important element in this respect. Essentially, sound affects our whole lives, whether it is sound in the work environment (hearing and health damage, or disturbance in mentally demanding professions) or in the home environment (resting, normal relaxation, culture). The housing factor is particularly important as we spend a substantial part of our lives there.

Partition building structures ensure acoustic comfort and quality in a wide range of spaces [1]. Methods for evaluating the structural-acoustic properties of partition structures have been used for a long time. Airborne sound insulation is the ability of a partition structure to transmit sound propagating through air from the source, i.e., from the source room, to the receiving room to a lesser extent. It is the difference between the levels of acoustic power incident on the structure and the power radiated by the structure.

According to Hongisto [2], airborne sound insulation is the most important physical quality determining the acoustic quality of buildings. Reinhard et al. [3] state that airborne sound insulation is mandatory to ensure a healthy living environment in buildings. According to [4], the measurement of 
airborne sound insulation of building elements in accordance with ISO 10140 at low frequencies is problematic. Airborne sound insulation is characterized by the sound reduction index (dB) in the $1 / 3$ octave frequency band from 100 to $3150 \mathrm{~Hz}$.

The sound reduction index (SRI), or sound transmission loss, is an acoustic quantity determined in laboratory conditions. The sound reduction index of partition structures can be influenced by the structural complexity of building openings, e.g., door. The authors Dlhý and Tomašovič. addressed this issue in their article [5]. They state that the structural complexity of the door causes difficulties in describing its behavior from an acoustic point of view. In many cases, even a small change can cause a large difference in the value of the sound reduction index of building structures. According to [6], when evaluating the sound reduction index of partition structures, the measurements made in real buildings are decisive, as they can confirm the suitability of using a particular partition structure. Authors in article [7] discussed the determination of the sound reduction index of building structures using a new measurement method based on the determination of the impulse response in two rooms separated by the partition. Erofeev and Monich [8] investigated the sound reduction index of sandwich panels in reverberation chambers in a diffuse sound field. Piana [9] determined the sound reduction index of prefabricated panels of large dimensions by means of point mobility measurement. Reboul and Pou [10] presented an alternative method of calculating the uncertainty of the weighted apparent sound reduction index using the Monte Carlo method.

White or pink noise is often used to excite a homogenous sound field. As reported by Balan et al. [11], pink and white noise are sounds with significantly different spectral characteristics. According to Moreno, the effect of the spectral composition of noise and the shape of the directional curve can have a significant effect on the acoustic properties of building structures [12]. Arjunan and Foteinou [13] investigated the acoustic behavior of free-standing partitions in an enclosed space using pink and white noise for the frequency range of 100 and $16 \mathrm{kHz}$ in the $1 / 3$ octave band. Buratti et al. [14] addressed the evaluation of the influence of different spectral composition of traffic noise in laboratory and real conditions, where, in addition to classical white and pink noise, all 14 spectra of traffic noise were tested. Prida et al. [15] discussed the sound reduction index of building structures and assessed the degree of correlation between nuisance perceived by humans and the most relevant existing SNQ (single number quantity) for a set of façade insulation elements and urban-type sound samples. A listening test was created using several sound samples, including pink noise. White and pink noise at various levels has also been used to monitor traffic and airport noise [16].

Changes in pulse waveforms while maximizing signal-to-noise ratios have been addressed in Regadio et al. [17]. In the article, the authors present the generalization of noise indices as a function of acoustic $f(\beta)$ type of noise, where beta was a real number. In 2015, Kaneda, Y., addressed the relationship between measurement signals and noise reduction power in his article [18]. He researched the noise reduction power characteristics of various measurement signals to derive equations, based on which it is possible to determine the noise reduction power from the measurement signal and noise spectrum.

The article builds on previous research published by Lumnitzer et al. [19]. Authors focused on verifying the impact of the type of noise used in determining the acoustic properties of partition structures. The research results confirmed that it is not necessary to define the type of noise for routine measurements. However, the choice of noise type is important at low frequencies. The authors of the research try to expand the area of knowledge in this specific area. They focused on excitation noise parameters such as frequency, excitation interval and type of excitation noise. These parameters are not considered in practice in current measurements; their choice, if possible, depends exclusively on the measurer, and no methodology specifies them. The information published so far does not bring a clear result. For this reason, the authors performed an extensive experiment with a statistically significant number of measurements. 


\section{Materials and Methods}

Excitation of diffusion field by noise is used when measuring the apparent sound reduction index. The measurer selects the parameters of this noise directly during the measurement. The decision is based on experience, recommendations, valid technical standards or the measurer discretionary chooses these parameters. To date, there is no methodology or scientifically based recommendations on how to choose these parameters so that they do not have an undesirable effect on the outcome of the measurement process. Authors draw on their experience and have conducted this research to prove which excitation parameters can affect the credibility of the results.

\subsection{Realization of the Experiment}

Experimental research was carried out in such a way that its outputs were characterized by the greatest possible degree of credibility. All identified uncertainties and impacts unrelated to the defined output were minimized. The experimental conditions were as follows:

- Given the number of performed measurements (in the order of hundreds), a constant state of the assessed building was ensured. Measurements were conducted over several weeks.

- The location of the measuring points was the same for all measurements in the source and receiving room.

- Background noise did not affect the measurements. This was repeatedly checked for all measurements. The choice of the building structure location was made with regard to this requirement.

- Measurement chain was calibrated before and after each measurement.

- For each measurement, sound pressure levels in the source and receiving room, background noise, and reverberation time in the receiving room were measured.

- The building structure was homogenous (no structural openings, no media distribution, and no use of different building materials). Its construction was made of one type of material (brick-thickness $300 \mathrm{~mm}$, plaster-15 mm), and it was built with emphasis on uniform properties over the entire surface of the structure. The partition under consideration was connected structurally to the side walls without the possibility of lateral sound transmission between the rooms.

- In both rooms, double-glazed windows with soundproof double glazing were installed, which prevented the transfer of acoustic energy between the rooms. A double-layer door was also installed. Perfect closing of windows and doors has been ensured during the measurement.

- For all set combinations of measurements (factors B and C), ten sets of measurements were performed, which is a statistically significant number.

Figure 1 shows one of the measuring points. The measurement situation with respect to the floor plan of the test rooms is shown in Figure 2. Considering the fact that we also focused on the area of low frequencies $(50 \mathrm{~Hz})$ in the experiment, the emphasis in the experiment was on the arrangement of the measurement so that it meets the requirements for the measurement of low frequencies. For this reason, three noise source positions and at least ten measuring points in each room were selected, the distance of measuring points from the wall of at least $1.2 \mathrm{~m}$ was guaranteed, and the size of the room was chosen so that at least one dimension was greater than the wavelength of the assessed sound (more than $50 \mathrm{~m}^{2}$ ). The dimensions of the room comply with the requirements of ISO 16283-1. Five measuring points in the receiving room were selected for the measuring of reverberation time. The measurements used verified measuring chains of accuracy class 1 , which are used in an accredited testing laboratory, are under continuous metrological control and linked to the international metrological standard. In order not to distort the sound field in the receiving and source room, only the measuring technician was present in the room during the measurements. 

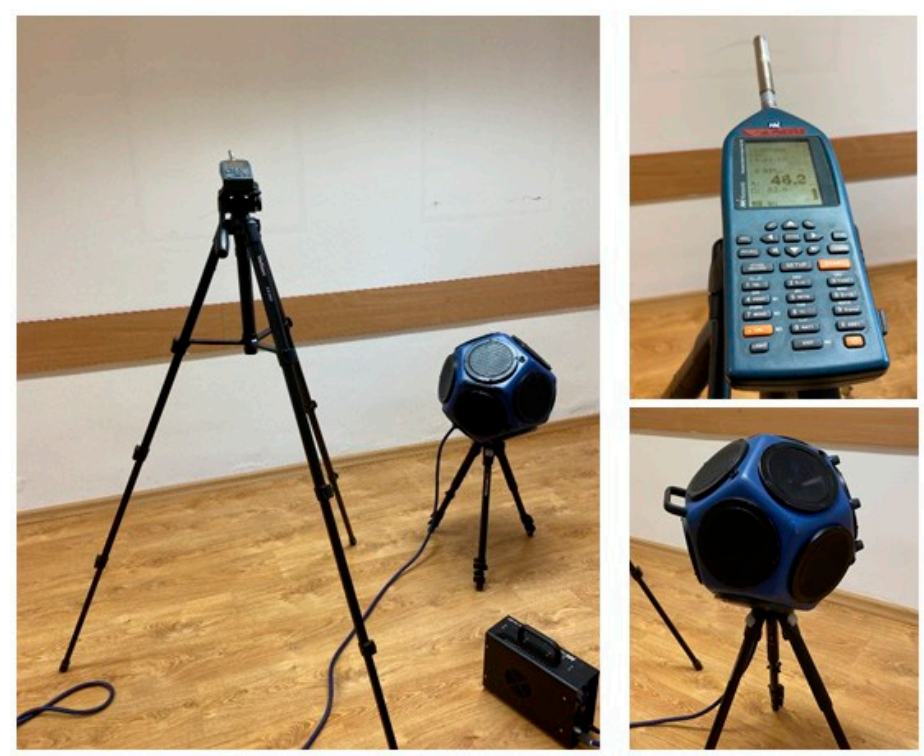

Figure 1. Measuring point and measuring equipment (sound source, microphone).
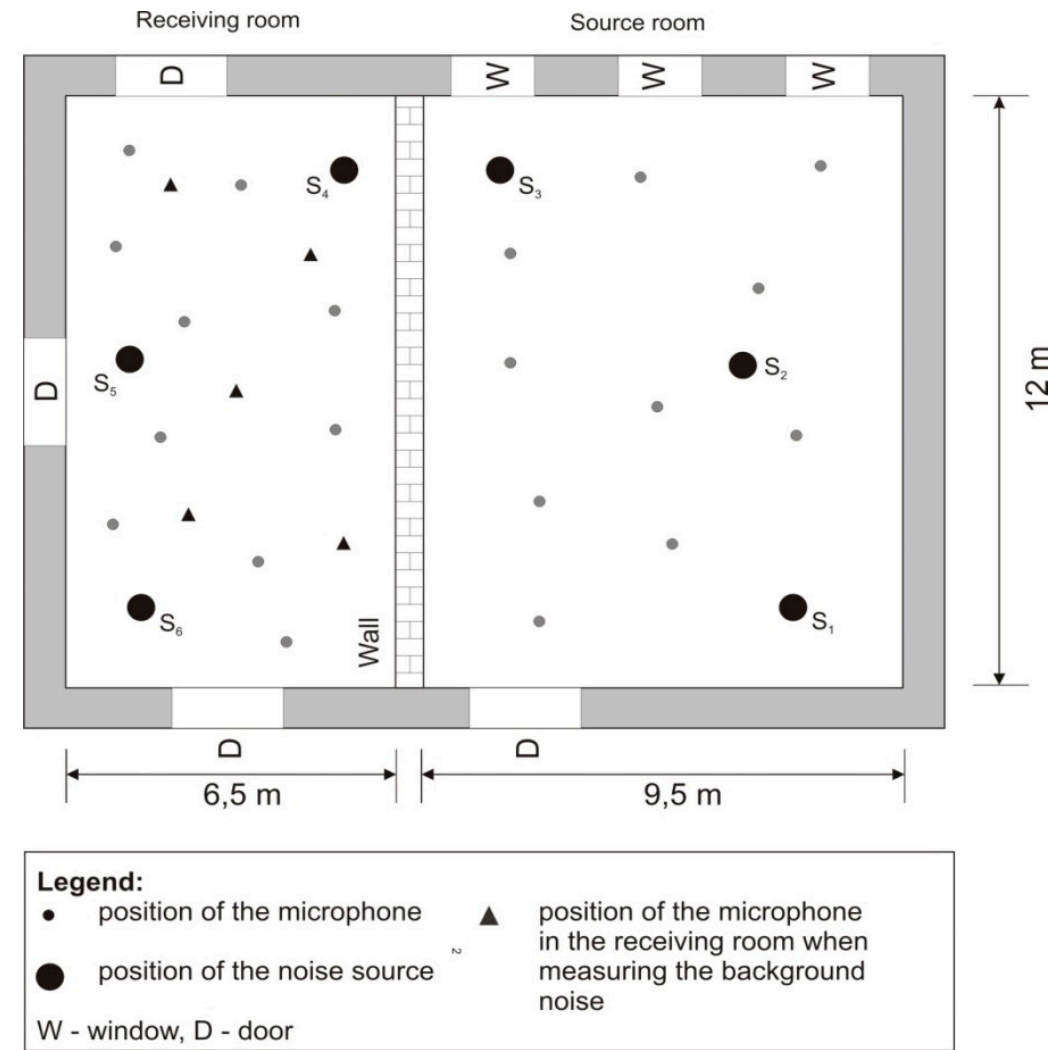

Figure 2. Floor plan of test rooms.

White or pink noise is used for the excitation of a homogenous sound field. White noise is a random signal (or process) with a flat power spectral density. In other words, in a homogeneous environment, the signal's power spectral density has equal power in any band, at any centre frequency, having a given bandwidth. For example, the $20 \mathrm{~Hz}$ range between 40 and $60 \mathrm{~Hz}$ has the same power as the range of frequencies between 4000 and $4020 \mathrm{~Hz}$. Pink noise, also known as 1/f noise, is a signal whose frequency density is proportional to the reciprocal of the frequency. When doubling the frequency, the energy falls by $3 \mathrm{~dB}$. It has equal power in constant percentage bandwidths, for example, octave bands. This corresponds to the logarithmic nature of human perception of sound. 
In Figure 3, a comparison of the frequency spectra of white and pink noise is shown. The spectrum displayed corresponds with the average value of the real generated white and pink noise of one set of ten measurements in the source room. It is evident that significant differences occur at low and high frequencies. Frequencies above $5 \mathrm{kHz}$ have not been addressed, as significant attenuation occurs in any building structure in these bands. From the figure below, the differences between theoretical and real frequency spectra of both types of noise are evident. These are brought about by the nature of noise source (the generator used had an equalizer available that was set in a way, that the noise generated matched the theoretical spectrum as closely as possible), linearity of the source, and the properties of the room (field diffusion). The character of the real frequency spectrum in individual sets of measurements was checked and kept within the minimum deviation values.

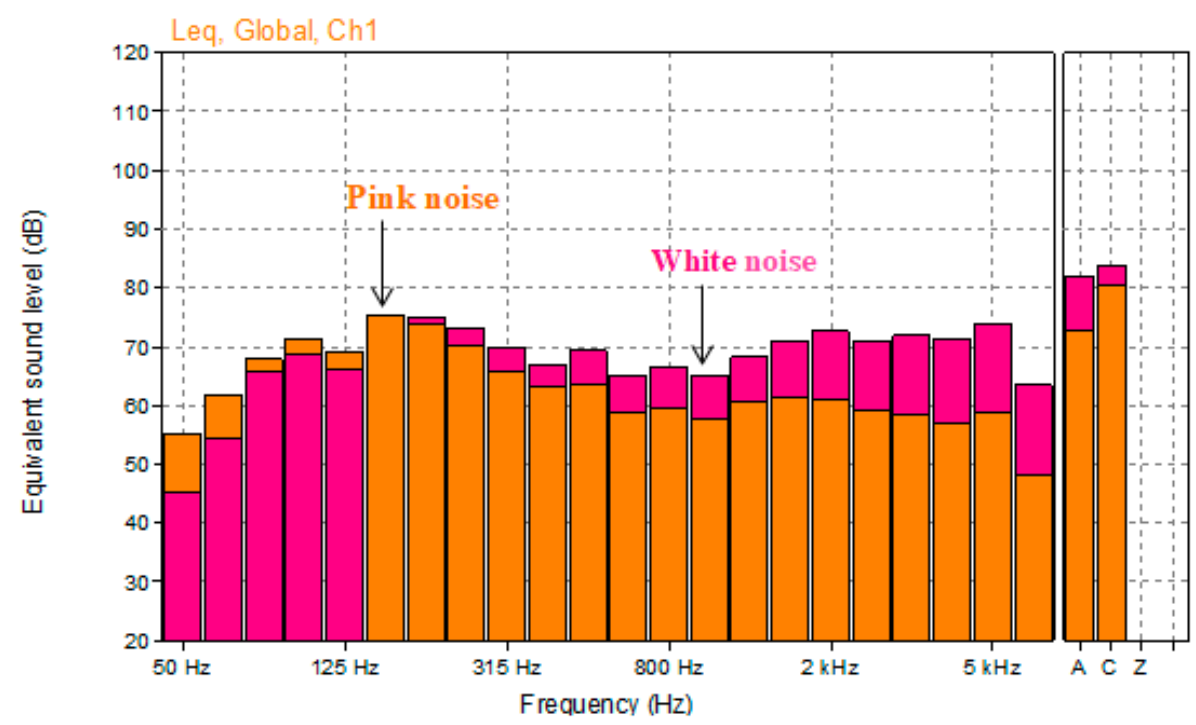

Figure 3. Comparison of average levels of real frequency spectrum of white and pink noise.

In all activities, special attention was paid to low frequencies, as these are currently problematic in terms of assessing building-acoustic properties. At low frequencies, the implementation of building-acoustic measures is difficult, and the subjective effect on humans is often more significant than the effect at high frequencies.

Three factors were chosen for the conduct of the experiment: frequency (factor A), excitation interval (factor B), and type of excitation noise (factor C). The factors were assessed equally in all experiments performed.

1. Factor A. When evaluating the test, the results were divided into three frequency intervals with the following ranges (F1, F2): Interval I (from 50 to $100 \mathrm{~Hz}$ ), Interval II (from 125 to $500 \mathrm{~Hz}$ ), and Interval III (from 630 to $1000 \mathrm{~Hz}$ )). The low level of factor A is always determined by the low limit F1 and the high level by the limit F2 of the respective frequency interval. In all activities, special attention was paid to low frequencies, as these are currently problematic in terms of assessing building-acoustic properties. At low frequencies, the implementation of building-acoustic measures is difficult, and the subjective effect on humans is often more significant than the effect at high frequencies. Based on authors' previous research, we focused on the frequency spectrum from 50 to $1000 \mathrm{~Hz}$ when evaluating the results of the experiment, despite the fact that the measurements were performed in the standard measuring range. The differences in the measured values at frequencies above $1000 \mathrm{~Hz}$ were below the significance limit.

2. Factor B. In the case of factor B, we considered the excitation interval in the range in which the lower middle value is $76 \mathrm{~dB}$ and the upper excitation interval with a mean value of $100 \mathrm{~dB}$. This interval was divided into partial intervals. Pink and white noise were excited in the source room at six selected excitation intervals: 75-78, 80-83, 85-88, 90-93, 95-98 and 98-102 dB. All values measured at the corner 
measuring points in the source room at a specific excitation setting are in the range of one interval (e.g., $75-78 \mathrm{~dB}$ ). The measurements were performed in $1 / 3$ octave bands so that it was possible to record temporally and spatially averaged measurements of sound pressure levels at several positions of the noise source. Sound pressure levels were recorded with $125 \mathrm{~ms}$ sampling.

3. Factor $C$ had two levels: white noise and pink noise, see Figure 3.

The basic quantities that evaluate the apparent sound reduction index $\mathrm{R}^{\prime}(\mathrm{dB})$, which characterizes the ability of the partition structure to transmit acoustic power propagating through the air from the source to the receiving room, are given in the STN EN ISO 16283-1 standard.

Apparent sound reduction index $R^{\prime}$ is calculated according to the equation

$$
R^{\prime}=L_{1}-L_{2}+10 \log \frac{S}{A}
$$

where $L_{1}$ is average sound pressure level in the source room $(\mathrm{dB}), L_{2}$ is average sound pressure level in the receiving room $(\mathrm{dB}), S$ is area of the partition structure $\left(\mathrm{m}^{2}\right)$ and $A$ is equivalent sound absorption area of the receiving room.

In determining the equivalent sound absorption area of the receiving room $A$, we start from the Sabine's equation

$$
A=\frac{0.16 V}{T}
$$

where $V$ is the volume of the receiving room $\left(\mathrm{m}^{3}\right)$ and $T$ is reverberation time in the receiving room (s). The equivalent sound absorption area depends on the nature of the receiving room, the surface of the walls, its equipment and shape.

\subsection{Evaluation Methods}

\subsubsection{DOE Methods}

The DOE (Design of Experiments) method is a sequence of pre-planned experiments in which the corresponding changes in the output variable (so-called echoes) are monitored by a purposeful change of input factors. The method makes it possible to identify the factors entering the process, or their interactions, which have a significant, decisive influence on the observed output variable.

When planning the experiment, we will use a two-level experiment in which each factor has only two levels: the low (" -") and the high ("+") level. In our case, it will be a complete $2^{\mathrm{k}}$ factor plan. In such an experiment, the main effect of factor $F$ is calculated as the difference between average values of the output variable $\mathrm{Y}$ at the high and low level of factor $\mathrm{F}$. A positive result of the effect of the factor means that increasing the factor $\mathrm{F}$ also increases the monitored output variable $\mathrm{Y}$. The DOE method was implemented using the Minitab programme.

\subsubsection{Regression and Correlation Analysis}

The relation between the output (dependent) and $\mathrm{k}$ input (independent) variables $X_{i}, i=1,2, \cdots$, $k$, can be expressed using a multiple linear regression model in the general form

$$
Y=\beta_{0}+\sum_{i=1}^{k} \beta_{i} X_{i}+\varepsilon
$$

where $\beta_{0}$ and $\beta_{i}$ for $i=1,2, \cdots, k$ are the parameters of the regression model and $\varepsilon$ is a random error.

The parameters of the regression model are estimated using the method of least squares. The F-test of the statistical significance of the model is used to verify the statistical significance of the regression model. When testing statistical hypotheses, the $p$-value is used. If the $\mathrm{p}$-value is lower than the specified level of significance $\alpha$, then we reject the null hypothesis in favour of the alternative hypothesis. If the 
$\mathrm{p}$-value is equal to or greater than the specified level of significance $\alpha$, then we do not reject the null hypothesis.

The strength of the dependence of the output variable $Y$ on the combined effect of the k-explanatory variables is expressed by the multiple coefficient determination $\mathrm{r}^{2}$. The coefficient takes values from the interval $\langle 0 ; 1\rangle$. The closer the value is to 1 , the tighter the dependence. A scale was used to evaluate the degree of dependence: no correlation $(|\mathrm{r}|<0.29)$, weak correlation $(0.30<|\mathrm{r}|<0.49)$, medium correlation $(0.50<|\mathrm{r}|<0.79)$ and strong correlation $(\mathrm{S}, 0.80<|\mathrm{r}|<1)$.

\section{Results and Discussion}

Experimental tests and subsequent processing of results were performed in order to:

- Determine the effect of factors on the apparent sound reduction index of building partition using the method of planning experiments;

- Analyze the dependence of the extent of the apparent sound reduction index on the input parameters (frequency and excitation interval) for both types of noise in the monitored frequency intervals;

- Analyze the dependence of the extent of apparent sound reduction index on the input parameters (frequency, excitation interval, type of noise) in the monitored frequency intervals.

To increase the reliability of the results, more measuring points than prescribed by technical standards were used in all measurements. The average sound pressure level is a representative value, which defines the excitation in the source room as well as the acoustic situation in the receiving room.

Graphical representation of the average sound pressure level for selected excitation intervals in the source and receiving room is shown in Figures 4 and 5.

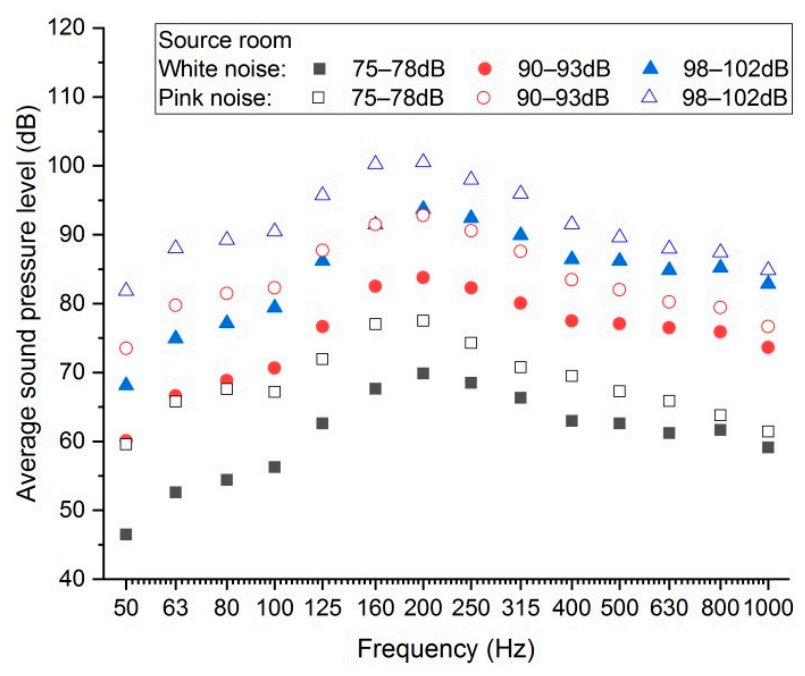

Figure 4. Average sound pressure level-source room. 


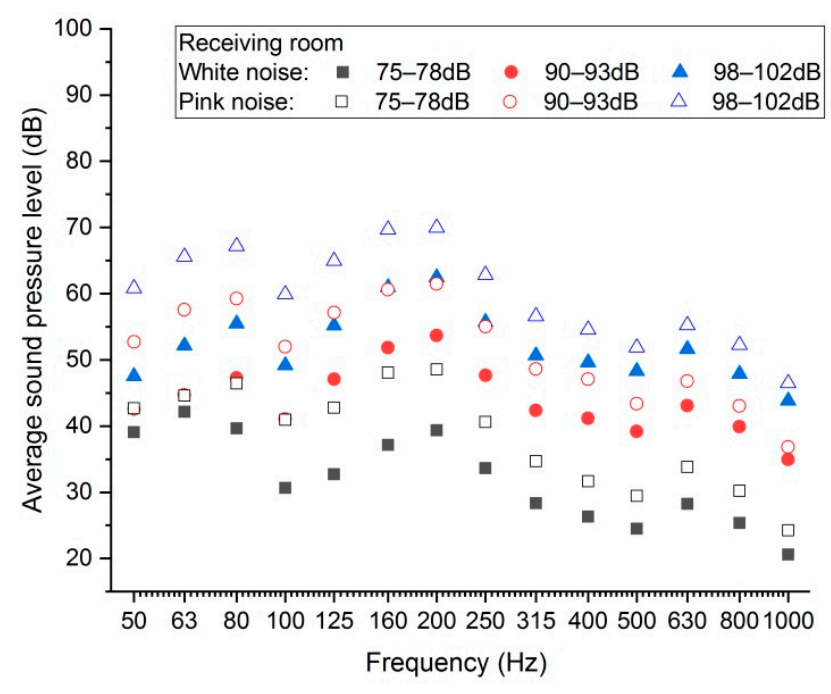

Figure 5. Average sound pressure level—receiving room.

Values measured at the medium frequencies of 50, 63, and $80 \mathrm{~Hz}$ show signs of instability. Their plausibility was confirmed by repeated measurements; ten complete sets of measurements were performed for each setting, a total of several hundred measurements were performed. From the obtained average measured values of sound pressure in the transmission and receiving room, the apparent sound reduction index $\mathrm{R}^{\prime}$ was calculated for individual excitation intervals. A graphical representation of the apparent sound reduction index for pink and white noise in the three selected excitation intervals can be seen in Figure 6.

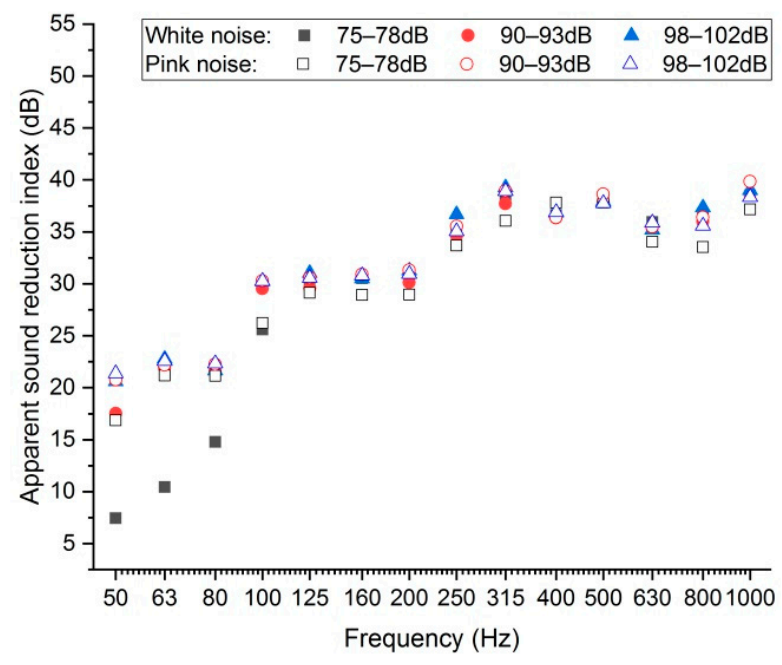

Figure 6. Apparent sound reduction index in three excitation intervals (white, pink noise).

In all excitation intervals, the apparent sound reduction index increases for frequencies up to $500 \mathrm{~Hz}$, then at a frequency of $630 \mathrm{~Hz}$ it slightly decreases.

In Figure 7, we can see a graphical representation of deviations of the apparent sound reduction index when using pink or white noise in excitation at individual frequencies and excitation intervals. The most significant differences in the apparent sound reduction index between the white and pink noise occur in the range from 50 to $100 \mathrm{~Hz}$. 


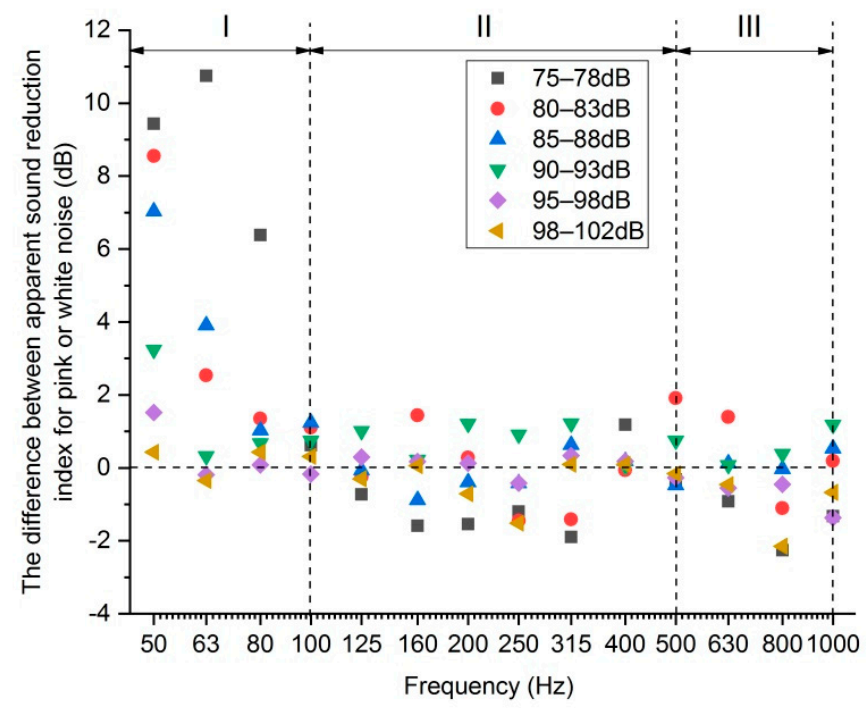

Figure 7. Difference between apparent sound reduction index for pink or white noise.

The most significant differences in the apparent sound reduction index between the white or pink noise occur in the range from 50 to $100 \mathrm{~Hz}$. Therefore, in the subsequent analysis, we will consider three frequency intervals: up to $100 \mathrm{~Hz}$, from 100 to $500 \mathrm{~Hz}$ and the interval from 500 to $1000 \mathrm{~Hz}$.

\subsection{Monitoring the Influence Of Factors On The Apparent Sound Reduction Index-DOE Method}

At the beginning of the planning, the objective of the experiment, input factors, and monitored outputs of the process were determined. In our case, a complete factor plan with three factors was chosen: frequency (factor A), excitation interval (factor B), and the type of excitation noise (factor C). Each of the input factors acquired two levels.

The objective of the experiment was to determine which of the considered factors or their interactions significantly affect the apaprent sound reduction index of the partition structure $(\mathrm{dB})$. Input factors and their levels are shown in Table 1.

Table 1. Input factors and their levels in the experiment with three factors.

\begin{tabular}{|c|c|c|c|}
\hline \multirow{2}{*}{ Designation } & Frequency (Hz) & Excitation Interval (dB) & Type of Noise \\
\hline & A & B & $\mathrm{C}$ \\
\hline Low $(-)$ & F1 & 76 & White \\
\hline High (+) & $\mathrm{F} 2$ & 100 & Pink \\
\hline
\end{tabular}

The effects of all main factors (A, B, and C) are given in Table 2.

Table 2. Effects of main factors.

\begin{tabular}{ccccc}
\hline \multirow{2}{*}{ Frequency Interval (Hz) } & \multicolumn{3}{c}{ Factors } \\
\cline { 3 - 5 } & & $\mathbf{A}$ & $\mathbf{B}$ & $\mathbf{C}$ \\
\hline \multirow{2}{*}{ I } & effect & 18.190 & 8.675 & 5.075 \\
& $\boldsymbol{p}$-value & $0.003^{*}$ & $0.009 *$ & $0.049 *$ \\
\hline \multirow{2}{*}{ II } & effect & 8.023 & 1.243 & -0.262 \\
& $\boldsymbol{p}$-value & $0.0001 *$ & $0.040^{*}$ & 0.583 \\
\hline \multirow{2}{*}{ III } & effect & 4.258 & 0.382 & -0.117 \\
& $p$-value & $0.0001 *$ & 0.146 & 0.610 \\
\hline
\end{tabular}

${ }^{*} p$-value is $<0.05$. 
The significance of individual effects of factors is tested by means of a t-test and determination of the p-value. The evaluation of the performed/conducted experiment shows that in the frequency band Frequency I, the current frequency (18.190; factor A) has the greatest effect on the observed response. The excitation interval (8.675; factor B) and the type of noise (5.075; factor C) have a significantly lower effect. In this band, all three main factors have a significant effect on the apparent sound reduction index (see Table 2).

Factors A and B have a statistically significant effect on the apparent sound reduction index also in the frequency Interval II. Compared to frequency Interval I, the effect of these factors is significantly lower (8.023; factor A, 1.243; factor B). The effect of factor C (noise type) was not confirmed in this interval (see Table 2).

The effect of factor A on the apparent sound reduction index is also in the third Interval III. In this interval, the effect of the other two factors $B$ and $C$ on apaprent sound reduction index was not confirmed (see Table 2).

\subsection{Regression Model I}

In creating a multiple regression model for two types of noise, we considered the apparent sound reduction index variable as a function of two input variables-frequency and excitation interval-i.e., we consider the function

$$
R^{\prime}=f(F, I)
$$

where $R^{\prime}$ is the apaprent sound reduction index, $F$ is the frequency $(\mathrm{Hz})$ and $I$ is the mean value of excitation interval $(\mathrm{dB})$. The frequency $F$ is varied between 50 and $1000 \mathrm{~Hz}$. For the excitation Interval I, we considered six intervals: 75-78, 80-83, 85-88, 90-93, 95-98, and 98-102 dB.

In the case of frequency Interval I (frequency from 50 to $100 \mathrm{~Hz}$ ), the best regression model (Model Ia) has the form (regardless of noise type)

$$
R^{\prime}=b_{0}+b_{1} F+b_{2} I
$$

For the Frequency Interval II (frequency from 120 to $500 \mathrm{~Hz}$ ), as well as for the Frequency Interval III (frequency from 630 to $1000 \mathrm{~Hz}$ ), the best regression model (Model Ib) has the form (regardless of noise type)

$$
R^{\prime}=b_{0}+b_{1} F
$$

Point estimates of parameters of multiple regression models and values of determination indices are given in Table 3.

Table 3. Parameters of Regression Model I.

\begin{tabular}{ccccc}
\hline & $\mathbf{b}_{\mathbf{0}}$ & $\mathbf{b}_{\mathbf{1}}$ & $\mathbf{b}_{\mathbf{2}}$ & $\mathbf{r}^{\mathbf{2 *} \mathbf{1 0 0} \boldsymbol{0}}$ \\
\hline White & & & & \\
Interval I & -26.54 & 0.255 & 0.316 & 84.3 \\
Interval II & 26.75 & 0.023 & - & 76.2 \\
Interval III & 29.59 & 0.009 & - & 87.6 \\
$\quad$ Pink & & & & \\
Interval I & 3.428 & 0.171 & 0.082 & 78.2 \\
Interval II & 27.35 & 0.024 & - & 76.8 \\
Interval III & 30.03 & 0.008 & - & 71.8 \\
\hline
\end{tabular}

To verify the statistical significance of all abovementioned models, we used the F-test of the model statistical significance. In all models, the resulting $\mathrm{p}$-value is less than the considered level of significance $\alpha$ ( $\alpha=0.05)$, so we can assume that the proposed regression models are statistically significant. We verified the statistical significance of the parameters of the regression models using the test of statistical significance of regression parameter. The results show that all parameters of 
the proposed regression models are statistically significant. In all the cases considered, there is a strong dependence.

Regression Model I shows a significant increase in the coefficient $b_{1}$ (see Table 3), which is related to the significant effect of low frequencies. We consider the difference in this coefficient to be significant in this regression model at frequencies up to $100 \mathrm{~Hz}$ (Interval I: white noise 0.255 , pink noise 0.171 ). Conversely, at higher frequencies, this difference is negligible (Interval II: White noise 0.023, pink noise 0.024; Interval III: white noise 0.009 , pink noise 0.008). The minimal difference of the coefficients is evident, as well as a significant decrease in the values of these coefficients themselves.

\subsection{Regression Model II}

In the next step, we observe the dependence of the apparent sound reduction index on the frequency, the excitation interval and the type of noise. In this case, we consider the output variable $R^{\prime}$ as a function

$$
R^{\prime}=f(F, I, N)
$$

where $R^{\prime}$ is the apaprent sound reduction index, $F$ is the frequency $(\mathrm{Hz}), I$ is the excitation interval $(\mathrm{dB})$, and $N$ is the type of noise used (white or pink noise).

It is apparent that, for the frequency Interval I (frequency from 50 to $100 \mathrm{~Hz}$ ), the best regression model has the form (Model IIa)

$$
R^{\prime}=b_{0}+b_{1} F+b_{2} I+b_{3} N
$$

For the frequency Interval II (frequency from 125 to $500 \mathrm{~Hz}$ ), the best regression model has the form (Model IIlb)

$$
R^{\prime}=b_{0}+b_{1} F+b_{2} I
$$

For the frequency Interval III (frequency from 630 to $1000 \mathrm{~Hz}$ ), the best regression model has the form (Model IIc)

$$
R^{\prime}=b_{0}+b_{1} F
$$

Point estimates of parameters of multiple regression models and values of determination indices are given in Table 4 . In all cases, the observed regression model is statistically significant. The parameters of the model are statistically significant as well.

Table 4. Parameters of Regression Model II.

\begin{tabular}{cccccc}
\hline & $\mathbf{b}_{\mathbf{0}}$ & $\mathbf{b}_{\mathbf{1}}$ & $\mathbf{b}_{\mathbf{2}}$ & $\mathbf{b}_{\mathbf{3}}$ & $\mathbf{r}^{\mathbf{2}} \mathbf{1 0 0} \%$ \\
\hline $\begin{array}{c}\text { Interval I } \\
\text { Model IIa }\end{array}$ & -12.827 & 0.213 & 0.198 & 2.541 & 77.1 \\
\hline $\begin{array}{c}\text { Interval II } \\
\text { Model IIb }\end{array}$ & 24.511 & 0.024 & 0.033 & - & 75.5 \\
\hline $\begin{array}{c}\text { Interval III } \\
\text { Model IIc }\end{array}$ & 29.810 & 0.008 & - & - & 78.8 \\
\hline
\end{tabular}

A graphical representation of the residuals, i.e., the differences between the theoretical values obtained from Regression Model II (Model IIa, Model IIb, Model IIc) and the experimental (measured) values for all excitation intervals, is shown in Figure 8. The most significant differences are in the frequency band up to $100 \mathrm{~Hz}$. 


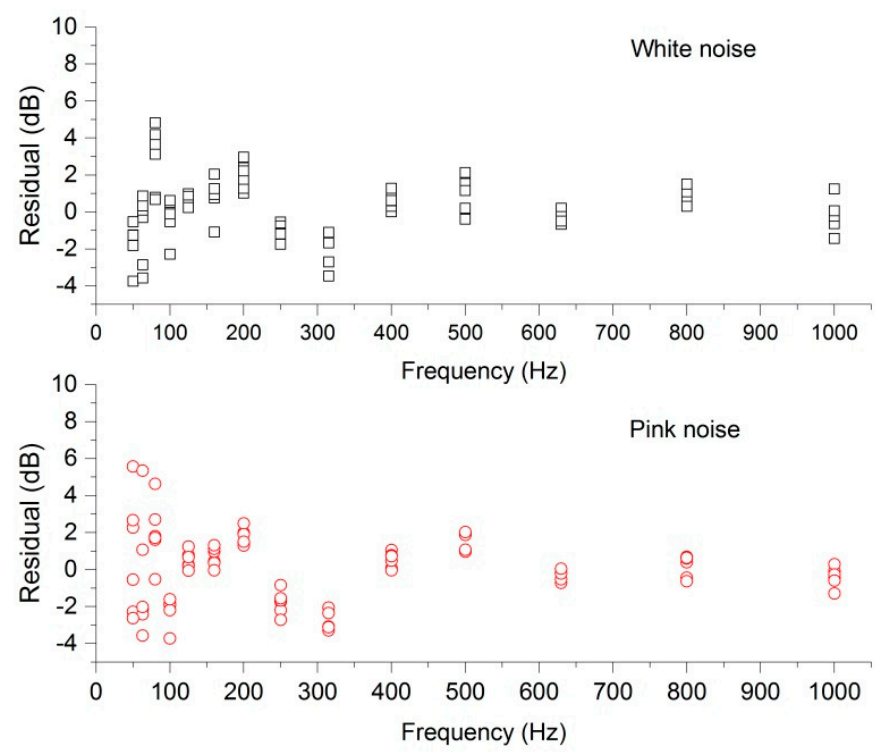

Figure 8. Scatter plot of residuals for both types of noise (regression Model II).

The summary of the effect of parameters on the apaprent sound reduction index in individual frequency intervals is shown in Table 5.

Table 5. Summary of the effect of parameters on the apparent sound reduction index.

\begin{tabular}{cccc}
\hline Parameters & Interval I & Frequency interval & Interval III \\
\cline { 2 - 4 } Frequency & $\begin{array}{c}\text { Changing the frequency } \\
\text { value significantly } \\
\text { affects the apaprent } \\
\text { sound reduction index }\end{array}$ & $\begin{array}{c}\text { Changing the frequency } \\
\text { value significantly } \\
\text { affects the apaprent } \\
\text { sound reduction index }\end{array}$ & $\begin{array}{c}\text { Changing the frequency } \\
\text { value affects the } \\
\text { apaprent sound } \\
\text { reduction index }\end{array}$ \\
\hline Excitation interval & $\begin{array}{c}\text { Changing the excitation } \\
\text { interval significantly } \\
\text { affects the apaprent } \\
\text { sound reduction index }\end{array}$ & $\begin{array}{c}\text { Changing the excitation } \\
\text { interval does not affect } \\
\text { the apaprent sound } \\
\text { reduction index }\end{array}$ & $\begin{array}{c}\text { Changing the excitation } \\
\text { interval does not affect } \\
\text { the apaprent sound } \\
\text { reduction index }\end{array}$ \\
\hline Noise type & $\begin{array}{c}\text { Changing the type of } \\
\text { noise affects the } \\
\text { apaprent sound } \\
\text { reduction index }\end{array}$ & $\begin{array}{c}\text { Changing the type of } \\
\text { noise does not affect the } \\
\text { apaprent sound } \\
\text { reduction index }\end{array}$ & $\begin{array}{c}\text { Changing the type of } \\
\text { noise does not affect the } \\
\text { apaprent sound } \\
\text { reduction index }\end{array}$ \\
\hline
\end{tabular}

\section{Conclusions}

In the experiments, the two most commonly used types of noise-pink and white-were chosen for excitation in the source room.

The analysis of experimental research leads to several conclusions:

- Regression Model I, which was focused on assessing the effect of frequency and excitation interval on the apparent sound reduction index, shows the independence of the results from the excitation interval for frequencies above $120 \mathrm{~Hz}$. This means that, in the case of routine assessments (for example, in the indicative determination of the airborne sound insulation of building structures), it is not important to pay attention to the intensity of sound field excitation in the source room, while the basic recommendations given in technical standards must be observed.

- Regression Model II, which was focused on assessing the effect of frequency, excitation interval and type of noise used on apparent sound reduction index, shows the independence of the results from the type of noise used in two frequency intervals (Interval II, Interval III). Again, the independence 
of results from the excitation interval for frequencies above $120 \mathrm{~Hz}$ and a significant dependence at frequencies up to $120 \mathrm{~Hz}$ are confirmed, which is evident from the scatter plot of residues for both types of noise (see Figure 8). The impact of frequency on the results of determination of airborne sound insulation of building structures is significant in all frequency intervals. On the other hand, in the area of low frequencies (below $100 \mathrm{~Hz}$, Interval I), the results of determining the apparent sound reduction index are significantly affected by the values of the investigated frequency interval and the used excitation interval. The influence of the noise type also manifests itself in this frequency interval.

For practice, it is important to realize that, if it is necessary to assess acoustic properties of building structures for frequencies below $100 \mathrm{~Hz}$, it is important to consider the assessment using both types of noise. For evaluation and prediction, a lower value of the sound reduction index should always be used.

From the conclusion of the evaluation, the authors came to the objectives of further research, which consists in replacing the currently used noises in the generation of the sound field with a real sound occurring in the assessed areas (loud sound of a television set, music of various genres, loud speaking). Improving the acoustic quality of the indoor environment in which we spend the most of our lives is now a task of increasing importance. It is proving necessary to develop new and more accurate models for assessing the acoustic quality of interiors. The authors consider the implementation of psychoacoustic properties in the processes of assessing interior spaces, as well as properties of partition structures, to be a promising direction.

Author Contributions: Conceptualization, M.A., E.L.; Methodology, M.A. and E.L.; Software, M.A.; Validation, M.A. and E.L.; Formal analysis, M.A., E.L. and A.Y; Investigation, M.A. and E.L.; Resources, A.Y.; Data curation, M.A. and A.Y.; Writing—original draft preparation, M.A., E.L. and A.Y.; Writing—review and editing, A.Y.; Visualization, M.A.; Supervision, E.L.; Project administration, A.Y.; Funding acquisition, E.L. All of the authors have read and agreed to the published version of this manuscript.

Funding: This article was prepared with support from the project titled KEGA 032 TUKE-4/2018 "Intensification of education and information processes in engineering for quality of the environment" and the project titled KEGA 002TUKE-4/2019 "Modern technologies and innovations in the education of physics at FMT TUKE".

Conflicts of Interest: The authors declare no conflict of interest.

\section{References}

1. Stephens, D. Measurement of sound insulation with a sound level meter. Appl. Acoust. 1976, 9, $131-138$. [CrossRef]

2. Hongisto, V. Airborne Sound Insulation of Wall Structure-Measurement and Prediction Methods. Doctoral Dissertation, Helsinki University of Technology, Helsinki, Finland, 2000. Available online: https://core.ac.uk/ download/pdf/80701311.pdf (accessed on 20 November 2020).

3. Reinhard, O.; Jian, K. Airborne sound insulation in terms of a loudness model. Appl. Acoust. 2014, 85, 34-35.

4. Roozen, N.B.; Leclere, Q.; Urban, D. Mobility based measurement of the airborne sound insulation R at low frequencies. In Proceedings of the 26th International Congress on Sound and Vibration, Montreal, QC, Canada, 7-11 July 2019.

5. Dlhý, D.; Tomašovič, P. Sound insulation determination of door. Adv. Build. Constr. Mater. II 2014, 1057, 215-222. [CrossRef]

6. Čulik, M.; Jochim, S.; Ondrejka, V. Sound insulation of partition wall and ceiling in panel timber frame structure. Akustika 2019, 31, 145-152.

7. Bonfiglio, P.; Fausti, P. Determination of sound reduction index by impulse response measurements. Acustica 2004, 14, 8 .

8. Erofeev, V.I. Sound insulation properties of sandwich panels. IOP Conf. Ser. Mater. Sci. Eng. 2020, 896, 012005. [CrossRef]

9. Piana, E.A. Method for determining the sound reduction index of precast panels based on point mobility measurements. Appl. Acoust. 2016, 110, 72-80. [CrossRef] 
10. Reboul, F.; Pou, J.M. Airborne sound insulation in buildings-Calculation of uncertainty of the weighted apparent sound reduction index, R'w, according to the Monte Carlo methods. In Proceedings of the 17th International Congress of Metrology, Paris, France, 21-24 September 2015.

11. Balan, O.; Moldoveanu, F.; Morar, A.; Asavei, V. Experiments on Training the Sound Localization Abilities: A Systematic Review. Let's build the future through learning innovation 2014. In Proceedings of the 10th International Scientific Conference on eLearning and Software for Education, Bucharest, Romania, 24-25 April 2014; Volume 2, pp. 34-41.

12. Moreno, A. Factors influencing dB (A) ratings for sound insulation: Incident noise spectrum and shape of the transmission loss curve. J. Sound Vib. 1984, 97, 337-348. [CrossRef]

13. Arjunan, A.; Foteinou, A. A comparative study on the acoustic behaviour of free-standing curved and flat single panel screens in an open-plan enclosed environment. In Proceedings of the 46th International Congress and Exposition on Noise Control, Hong Kong, China, 27-30 August 2017.

14. Buratti, C.; Moretti, E.; Vergoni, M. Sound insulation performances of windows: evaluation of the influence of different traffic noise spectra in laboratory and field measurement. In Proceedings of the 17th international congress on sound and vibration, Cairo, Egypt, 18-22 July 2010.

15. De La Prida, D.; Pedrero, A.; Navacerrada, M. Ángeles; Díaz-Chyla, A. An annoyance-related SNQ for the assessment of airborne sound insulation for urban-type sounds. Appl. Acoust. 2020, 168, 107432. [CrossRef]

16. Marouf, S.S.; Bell, M.C.; Goodman, P.S.; Neasham, J.; Neasham, J.; Namdeo, A.K. Comprehensive study of the response of inexpensive low energy wireless sensors for traffic noise monitoring. Appl. Acoust. 2020, 169. [CrossRef]

17. Regadío, A.; Tabero, J.; Prieto, S.S. Impact of colored noise in pulse amplitude measurements: A time-domain approach using differintegrals. Nucl. Instrum. Methods Phys. Res. Sect. A Accel. Spectrometers Detect. Assoc. Equip. 2016, 811, 25-29. [CrossRef]

18. Kaneda, Y. Noise reduction performance of various signals for impulse response measurement. J. Audio Eng. Soc. 2015, 63, 348-357. [CrossRef]

19. Lumnitzer, E.; Andrejiova, M.; Bodnárová, A.G. Verification of the impact of the used type of excitation noise in determining the acoustic properties of separating constructions. Measurments 2016, 78, 83-89. [CrossRef]

Publisher's Note: MDPI stays neutral with regard to jurisdictional claims in published maps and institutional affiliations.

(C) 2020 by the authors. Licensee MDPI, Basel, Switzerland. This article is an open access article distributed under the terms and conditions of the Creative Commons Attribution (CC BY) license (http://creativecommons.org/licenses/by/4.0/). 